\title{
FEDERAL RESERVE BANK OF SAN FRANCISCO
}

WORKING PAPER SERIES

\section{Macro Factors and the Affine Term Structure of Interest Rates}

\author{
Tao $\mathrm{Wu}$ \\ Federal Reserve Bank of San Francisco
}

January 2005

Working Paper 2002-06

http://www.frbsf.org/publications/economics/papers/2002/wp02-06bk.pdf

The views in this paper are solely the responsibility of the authors and should not be interpreted as reflecting the views of the Federal Reserve Bank of San Francisco or the Board of Governors of the Federal Reserve System. 


\title{
Macro Factors and the Affine Term Structure of Interest Rates
}

\author{
Tao $\mathrm{Wu}^{*}$
}

January 2005

\begin{abstract}
This paper formulates an affine term structure model of bond yields from a dynamic stochastic equilibrium model, with observable macro state variables as the term structure factors. Model implications for the joint macro-term structure dynamics are consistent with the empirical patterns from the VAR estimation. Model calibration and simulation exercises also provide clear macroeconomic interpretations of the latent term structure factors as found in the finance literature: most of the "slope" factor movement can be explained by exogenous monetary policy shocks, and the "level" factor movement is closely related to the technology shocks.
\end{abstract}

${ }^{*}$ Special thanks go to Christopher Sims, Stefan Krieger, Hua He, Glenn Rudebusch, John Williams, and participants at the Macroeconomics and Econometrics seminars at Yale, Princeton, University of Pennsylvania, and the Western Finance Association. Email: tao.wu@sf.frb.org. Correspondence to: Tao Wu, Economic Research Department, Federal Reserve Bank of San Francisco, 101 Market Street, San Francisco, CA 94105. The views expressed herein are solely those of the author and not necessarily those of the Federal Reserve Bank of San Francisco or the Federal Reserve System. 


\section{Introduction}

The term structure of interest rates and macroeconomic activity are closely related. Bondtraders and financial analysts often cite monetary policy as a major factor in term structure movements, and the bond market is sensitive and responds quickly to macroeconomic news releases (Gürkaynak, Sack, and Swanson (2004)). Likewise, term structure movements convey important information about the future state of macroeconomy (Bernanke and Blinder (1992), Estrella and Hardouvelis (1991) and Mishkin (1990), among others). Yet few studies have examined the joint dynamics of the term structure and the macroeconomy in a general equilibrium setting. Most general equilibrium models in the macroeconomics literature do not incorporate long-term interest rates, and most term structure models in the asset pricing literature are either reduced-form or built in an endowment economy and do not explicitly take structural macro dynamics into consideration.

This paper proposes a framework that complements the standard general equilibrium models with the term structure of interest rates. Following the no-arbitrage-based asset pricing approach, interest rates of different maturities are found to be linear functions of macro state variables, whose dynamics are determined by the underlying general equilibrium models. Whereas this framework can be applied to various dynamic stochastic general equilibrium models, I focus on a quite standard New Keynesian general equilibrium model with costly price adjustment and capital adjustment, and examine the model's implications for the joint dynamics of macroeconomic aggregates and the term structure, which are found to be broadly consistent with the empirical pattern in the U.S. data. I also explore the economic nature of the latent term structure factors that are often used to describe the term structure movements (Knez, Litterman and Scheinkman (1994), Dai and Singleton (2000), Duffee (2002), among others) in the finance literature, and find that the commonly named "slope" factor is closely related to exogenous monetary policy shocks, and the "level" factor is primarily driven by the technology shocks.

Building such a joint macro-term structure framework pays off for reasearchers in both macroeconomics and finance. For macroeconomists who want to bring long-term interest rates into their analysis, this framework extends the macro general equilibrium models into a very tractable linear model of term structure using the rigorous no-arbitrage based asset-pricing approach, which is central to modern finance literature. For financial economists, this framework provides a solid macroeconomic basis for understanding how various fundamental macroeconomic 
shocks affect the determination of term structure factors and future term structure movements.

This line of research is part of a rapidly growing literature exploring the relation between the term structure and macroeconomic dynamics. The canonical term structure studies in the finance literature do not take macroeconomic dynamics into consideration; rather, they assume that term structure movements are driven by a few latent factors (Litterman and Scheinkman (1991), Dai and Singleton (2000), Duffee (2002), among others) or a few linear combinations of interest rates with different maturities (Duffie and Kan (1996)) without a clear macroeconomic interpretation. Recent studies such as Kozicki and Tinsley (2001), Dewachter and Lyrio (2002) and $\mathrm{Wu}$ (2003) use the VAR framework to trace the effect of macroeconomic shocks on the term structure. Ang and Piazzesi (2003) and Ang, Piazzesi, and Wei (2004) apply the noarbitrage-based affine term structure modeling techniques to VAR models, and Rudebusch and Wu (2004a) and Hördahl, Tristani and Vestin (2004) further combine such techniques with reduced-form structural New Keynesian models. However, all of them are reduced-form analysis and are lack of a general equilibrium basis.

Only a few studies, which are in the consumption-based asset pricing literature, adopt the general equilibrium approach in modeling the term structure; these include the pioneering work of Cox, Ingersoll, and Ross (1985), followed by Constantinides (1992), Longstaff and Schwartz (1992), and Sun (1992). However, to obtain analytical term structure formulae, these studies often make very strong simplifying assumptions about the economy and, thus, are quite limited in examining the joint macro-term structure dynamics. Indeed, introducing complicated dynamic stochastic general equilibrium models into term structure analysis (and asset pricing in general) involves significant computational challenges. As such models often have no analytical solutions, the usual practice among macroeconomists is to linearize them and examine the first-order approximations of the model solution. The problem is, linearizing the Euler equations leads to "certainty equivalence," which implies that all kinds of assets would have identical returns, thus rendering it useless for asset pricing studies.

As an alternative strategy, various numerical algorithms can be used to solve the models and obtain nonlinear solutions as well as nonzero risk compensations. For instance, using "parameterizing expectations" algorithm, den Haan (1995) numerically solves a simple real business cycle (RBC) model with money and analyzes the behavior of the nominal term structure. Chapman (1997) adopts the same numerical algorithm to solve a RBC model and examine the 
cyclical properties of real term structure. Evans and Marshall (1998) uses a mixture of partial linearization, Gauss-Hermite quadrature, and a Monte Carlo method to solve their "limited participation" model and analyze monetary policy's effects on the nominal term structure. While these studies have made significant progress in analyzing the term structure in a more realistic general equilibrium environment, the computational burden it entails is so heavy that it is very difficult to introduce more complicated macroeconomic dynamics along this line.

In solving the dynamic stochastic general equilibrium model established in this paper, I adopt a two-step strategy: first I take a loglinearization of the model's Euler equations and solve the resulting linear system in the usual manner to yield a linear law of motion for the macro state variables; in the second step I lognormalize the relevant bond-pricing Euler equations and derive the risk compensation structure. This strategy, combined with the law of motion of macro state variables, enables me to formulate a Gaussian affine term structure model, in which bond rates of different maturities are all linear functions of the underlying macro state variables. This method provides a tractable alternative to the numerical methods discussed above and can be applied to various dynamic stochastic general equilibrium models.

The remainder of the paper is organized as follows. Section 2 estimates a recursive VAR model and summarizes a few stylized facts about the nominal term structure and business cycles in the post-war U.S. economy. Section 3 presents a New Keynesian dynamic stochastic general equilibrium model with sticky price adjustments, which is widely used by macroeconomists. Section 4 lays out the solution algorithm and derives the affine formulae for the term structure. Section 5 calibrates the model and examines the model implications for the joint behavior of the macroeconomy and the term structure. This section also explores the economic nature of the latent term structure factors found in the finance literature. Section 6 concludes.

\section{Stylized Facts from a Recursive VAR Estimation}

This section examines the empirical relationship between the nominal term structure and business cycles. Following Evans and Marshall (1998) and Wu (2003), I formulate the following recursive VAR model:

$$
\left[\begin{array}{ll}
a & b \\
c & 1
\end{array}\right]\left[\begin{array}{l}
Y_{t} \\
R_{t}
\end{array}\right]=\left[\begin{array}{ll}
A(L) & B(L) \\
C(L) & D(L)
\end{array}\right]\left[\begin{array}{c}
Y_{t-1} \\
R_{t-1}
\end{array}\right]+\Sigma\left[\begin{array}{c}
\varepsilon_{Y, t} \\
\varepsilon_{R, t}
\end{array}\right]
$$

where the macroeconomic vector $Y_{t}$ is defined as 
$Y_{t} \equiv\left(I P, E M, P C E P I, M_{2}, F F R, P C O M\right)^{\prime}$ where $I P$ is industrial production, $E M$ is nonagricultural payroll employment in the private sector, $P C E P I$ is the core PCE price index, $M 2$ is the monetary aggregate M2, FFR is the federal funds rate, and PCOM is Commodity Research Bureau's spot market price index for all materials. All macro data are in logarithms except for FFR. $R_{t}$, a term structure variable, can be either the 1-month, 3-month, 1-year, 2-year, or 5 -year nominal interest rate, or the "level" or "slope" of the term structure (parsimoniously defined as the equally weighted average of the five kinds of bond rates and the term spread between 5-year rate and 1-month rate, respectively). ${ }^{1}$ The bond yields are the Fama-Bliss zerocoupon U.S. Treasury bond yields data from CRSP. The process $\left(\varepsilon_{Y, t}, \varepsilon_{R, t}\right)^{\prime}$ is an i.i.d. vector of mutually and serially uncorrelated structural shocks. Assuming that current and past term structure shocks, $\varepsilon_{R, t}$, do not feed back to the monetary policy authority or the macroeconomy, both $b$ and $B(L)$ are set to zero.

The VAR is estimated over the sample period 1983:01 to 2002:12, with twelve lags assumed in each equation. Figure 1 displays the impulse responses of the macro variables $Y_{t}$ to onestandard deviation monetary policy shocks and real output (IP) shocks. The solid lines plot the point estimates and the dotted lines plot the $90 \%$ confidence bands drawn from Bayesian Monte Carlo simulations. Both the impulse responses and the confidence bands are measured in percentage deviations from the steady state.

A one-standard-deviation contractionary monetary policy shock has a significant but transitory effect on the federal funds rate, raising it by 17 basis points on impact and 21 basis points next month before it starts to fall and becomes trivial in one year. Monetary aggregate M2 falls during this period due to the liquidity effect. The shock also leads to gradual declines in output and employment. However, the price level does not fall in response to the shock, indicating a "price puzzle" as described in Sims (1992). On the other hand, a one-standard-deviation positive output shock leads to significant and persistent increases in industrial production and employment. The federal funds rate rises by only 2 basis point in the month of the initial shock and then gradually increases, reaching the maximal response of 12 basis points eight months after the shock before falling back to the original level two years after the shock. The shock, however, has insignificant effects on price level and on M2.

\footnotetext{
${ }^{1}$ The "level" and "slope" as intuitively defined above are well known to be highly correlated to the first two principle components of the term structure, which account for about $99 \%$ of the total variations of all bond yields in the sample period.
} 
Figure 2 plots the estimated responses of the term strcuture to the shocks. A one-standarddeviation contractionary monetary policy shock increases the 1-month rate by approximately 17 basis points in the month when the shock occurs. The 1-month rate continues to climb in the following months and then falls rapidly, with the responses become insignificant in about ten months. The 3-month and 1-year rates display qualitatively similar patterns, although the magnitude of the response decreases as the maturity increases. When we move to even longer maturities, the initial effect diminishes even more: the initial response of the 2-year bond rate is only about 7 basis points, and for the 5 -year bond rate, it is 5 basis points. Moreover, the longer the maturities are, the faster the responses die away: ten months for 1-month and 3-month rates, six months for 1-year rate, three months for 2-year rate and two months for 5-year rates.

The second column of Figure 2 shows that, in response to a one-standard-deviaton positive output shock, the 1-month bond rate rises and reaches its maximal of 12 basis points three months after the shock. In contrast to the monetary policy shock, the magnitude of output shock's effects is very similar across bond maturities: the 3-month and 1-year rates rise and reach the maximal of 11 and 13 basis points in the third months after the shock before they gradually decline, and the 2-year and 5-year bond rates increase by a maximal of 12 and 11 basis points in the second months after the shock. The term structure responses to the output shock are quite persistent: none of the effects dissipate away until twelve to eighteen months after the initial shock.

In summary, a contractionary monetary policy shock has large but short-lived effects on short-term bond rates, with decreasing effects on longer maturities. In other words, there is not a parallel upward shift of the term structure in response to such a shock, but rather a tilt that makes the yield curve flatter. An alternative way to portray these changes is to look directly at the effects on the shape of the yield curve: such a shock raises the "level" and decreases the "slope" of the yield curve, and most of the effects dissipate away in six months. Evans and Marshall (1998) have the similar findings on monetary policy shocks. In contrast, a positive output shock has significant and relatively more persistent effects on the term structure, which are quantitatively similar across different bond maturities. Such effects lead to a persistent upward shift of the "level" of the yield curve, but lead to little change in the "slope" of the yield curve. 


\section{A New Keynesian Model with Capital Adjustment Costs}

In this section I present the general equilibrium model for deriving the affine term structure in the next section. The model is formulated in a framework where monopolistically competitive firms face a quadratic cost when they adjust the nominal price of their product. Individual firms employ labor and accumulate physical capital by paying capital installation costs, and the monetary authority follows a short-rate feedback policy rule. The model economy has three types of entities: households, firms, and a government whose sole function is to create money and impose lump-sum taxes on households. The households own the firms, so all profits from the firms are paid to the households as dividends.

\section{Households}

The representative household carries $M_{t-1}$ units of money and a portfolio of nominal zerocoupon bonds with a maximal maturity of $J$ periods, denoted by $\left\{B_{j, t-1}\right\}_{j=1}^{J}$, into period $t .^{2}$ $B_{j, t}$ denotes the amount of the bond purchased at date $t$ that pays one dollar at the end of period $t+j-1$. During period $t$, the representative household supplies $N_{t}$ units of labor at the nominal wage rate $W_{t}$, receives real dividends $\Pi_{t}$ from the firms, and pays real lump-sum taxes $\tau_{t}$ to the government. The household purchases consumption goods $C_{t}$ at the nominal price $P_{t}$, adjusts its portfolio of nominal bonds, and carries $M_{t}$ and the new bond portfolio $\left\{B_{j, t}\right\}_{j=1}^{J}$ into the next period. Thus, the flow budget constraint that the representative household faces is

$$
C_{t}\left(1+\theta V_{t}\right)+\frac{M_{t}}{P_{t}}+\sum_{j=1}^{J} \frac{b_{j, t}}{P_{t}} B_{j, t}+\tau_{t}=\frac{W_{t}}{P_{t}} N_{t}+\Pi_{t}+\frac{M_{t-1}}{P_{t}}+\sum_{j=0}^{J-1} \frac{b_{j, t}}{P_{t}} B_{j+1, t-1},
$$

where $V_{t}=\frac{P_{t} C_{t}}{M_{t}}$ is the velocity of money. The representative household needs money because there are transaction costs in purchasing the consumption goods, and high real balances yield low transaction costs. Leisure, $L_{t}$, that the household enjoys in period $t$ is defined by

$$
L_{t}=1-N_{t} .
$$

\footnotetext{
${ }^{2}$ The time notation in this paper is such that any variable included in the information set of period $t$ has a time subscript $t$. Therefore, the amount of money inherited from last period is denoted by $M_{t-1}$, and the amount of money carried over to next period, since it is known in period $t$, is denoted by $M_{t}$. This is in contrast to the time notation that some other authors may choose, in which such terms may be denoted by $M_{t}$ and $M_{t+1}$, respectively.
} 
The representative household's preferences are described by the expected utility function

$$
E_{0} \sum_{t=0}^{\infty} \beta^{t} U\left(C_{t}, L_{t}\right),
$$

where $\beta \in(0,1)$ is a constant discount factor, and the single-period utility function takes the form

$$
U(C, L)=\frac{C^{\gamma(1-\phi)} L^{(1-\gamma)(1-\phi)}-1}{1-\phi} .
$$

This is a Constant Relative Risk Aversion $(C R R A)$ utility function, with $\phi$ as the coefficient of relative risk aversion. Consumption and leisure enter the household's utility through a CobbDouglas function. The household chooses $C_{t}, N_{t}, M_{t}$, and $\left\{B_{j, t}\right\}_{j=1}^{J}$ for each $t=0,1,2, \ldots$ to maximize its utility in equations (3.3) and (3.4) subject to the constraints in equations (3.1) and $(3.2)$.

\section{Firms}

For the structure of product markets, I adopt a monopolistic competition framework, along the lines of Blanchard and Kiyotaki (1987). At time $t$, a final consumption good, $C_{t}^{*}$, is produced by a perfectly competitive firm. It does so by combining a continuum of intermediate goods, indexed by $i \in(0,1)$, using the technology

$$
C_{t}^{*}=\left[\int_{0}^{1} C_{i, t}^{* \frac{1}{\mu}} d i\right]^{\mu}
$$

where $1 \leq \mu \leq \infty$ and $C_{i, t}^{*}$ denotes the time $t$ input of intermediate good $i$. Let $P_{t}$ and $P_{i t}$ denote the time $t$ prices of the final consumption good and intermediate good $i$, respectively. Profit maximization implies the Euler equation

$$
\left(\frac{P_{i, t}}{P_{t}}\right)^{-\eta}=\frac{C_{i, t}^{*}}{C_{t}^{*}},
$$

where $\eta=\frac{\mu}{\mu-1}$ is the elasticity of demand for intermediate good $i$. Thus the demand for product $i$ is a function of the relative price $P_{i, t} / P_{t}$ and the aggregate output of the final consumption good, $C_{t}^{*}$. Integrating (3.6) and imposing (3.5), we obtain the following relationship between the price of the final good and that of the intermediate goods:

$$
P_{t}=\left[\int_{0}^{1} P_{i, t}^{\frac{1}{1-\mu}} d i\right]^{(1-\mu)}
$$


Intermediate good $i$ is produced by the intermediate firm $i$ with the following production technology:

$$
Y_{i, t}=A_{t} K_{i, t-1}^{\alpha} N_{i, t}^{1-\alpha}-\Phi_{i, t}
$$

where $0<\alpha<1$. Here $A_{t}$ denotes the general productivity level in period $t, N_{i, t}$ and $K_{i, t-1}$ denote time $t$ labor and capital used to produce the intermediate good $i .^{3} \Phi_{i, t}$ denotes a fixed cost of production. I rule out entry into and exit from the production of intermediate good $i$ and calibrate the fixed cost to guarantee zero profits in steady state. The production technology $A_{t}$ follows an $\mathrm{AR}(1)$ process

$$
\ln \left(A_{t}\right)=\rho_{A} \ln A_{t-1}+\left(1-\rho_{A}\right) \ln A^{*}+\varepsilon_{A, t},
$$

where $\rho_{A} \in(-1,1)$ and the serially uncorrelated shock $\varepsilon_{A, t}$ is normally distributed with mean zero and standard deviation $\sigma_{A} . A^{*}>0$ is the logarithm of the steady-state technology level.

The intermediate firm $i$ accumulates physical capital stock, and the accumulation process is given by

$$
K_{i, t}=I_{i, t}+(1-\delta) K_{i, t-1}
$$

where $K_{i, t}$ is the amount of capital stock and $I_{i t}$ is the amount of physical investment in period $t$. The existing capital depreciates at a constant rate of $\delta$. The firm also faces capital adjustment costs in the form of

$$
A C_{i, t}^{K}=\frac{\chi_{K}}{2}\left(\frac{I_{i, t}}{K_{i, t-1}}\right)^{2} I_{i, t}
$$

The marginal adjustment cost of investment is positive and increases as investment increases.

Each intermediate firm sells its output to the producer of the final consumption goods in a monopolistically competitive market and is able to adjust the sales price of its output. However, each faces a real quadratic adjustment cost (per unit of sales) in the form of 4

\footnotetext{
${ }^{3}$ The capital stock used in production in this period is inherited from the last period; therefore, it carries a time subscript $(t-1)$ even though it is used in the production process in period $t$.

${ }^{4}$ Rotemberg (1982a, 1982b) introduces this quadratic form of price adjustment costs. Calvo (1983) develops another mechanism to introduce price stickiness by assuming that in each period only a fraction of firms can adjust their price and that this adjustment opportunity is allocated randomly across firms. As noted in King and Watson (1996), both mechanisms yield the same dynamic pricing processes for the firms.
} 


$$
A C_{i, t}^{P}=\frac{\chi_{P}}{2}\left[\frac{P_{i, t}}{P_{i, t-1}}-\left(1+\pi^{*}\right)\right]^{2},
$$

where $\pi^{*}$ is long-run inflation expectation which is identical to the monetary authority's explicit inflation target (set to zero in later calibrations), and $\chi_{P}$ is the parameter of the price-adjustment costs. $^{5}$

The intermediate firm $i$ chooses a plan for production, labor demand, pricing process, and investment so as to maximize the expected present value of its real profit flows, conditional on the information at time zero:

$$
\operatorname{Max} . E_{0} \sum_{t=0}^{\infty} \beta^{t} \rho_{t} \Pi_{i, t},
$$

where the real profit $\Pi_{i, t}$ is defined as

$$
\Pi_{i, t}=\frac{P_{i, t} C_{i, t}^{*}-W_{t} N_{i, t}}{P_{t}}
$$

and

$$
C_{i, t}^{*}=\left(1-A C_{i, t}^{P}\right) A_{t} K_{i, t-1}^{\alpha} N_{i, t}^{1-\alpha}-\Phi_{i, t}-I_{i, t}-A C_{i, t}^{K}
$$

The firm's discount factor is given by a stochastic process, $\left\{\rho_{t}\right\}$. In equilibrium, it represents a pricing kernel for real contingent claims. Since the markets are complete in this model, it equals the representative household's intertemporal marginal rate of substitution (IMRS) for an additional unit of consumption goods in period $t$.

\section{Monetary Authority}

The monetary authority's policy rule takes the form of an interest rate feedback rule, which is a reaction function of the short-term interest rate on the inflation and the real output gaps as well as on the lagged short-term interest rate:

$$
r_{1, t}=\rho_{r} r_{1, t-1}+\left(1-\rho_{r}\right)\left(r_{1}^{*}+\theta_{1}\left(\pi_{t}-\pi^{*}\right)+\theta_{2}\left(\ln y_{t}-\ln \bar{y}_{t}\right)\right)+\varepsilon_{r, t},
$$

\footnotetext{
${ }^{5}$ As argued in Ireland (1997) and Kim (2000), this specification implies that the agents in the economy adapt themselves to a stable inflation rate. Therefore, it is costly to increase prices in excess of this rate, both because of advertising costs and because an erratic pricing strategy causes consumer dissatisfaction.
} 
where $0<\rho_{r}<1, \theta_{1}>1-\rho_{r}$, and $\theta_{2}>0 . r_{1}^{*}$ is the unconditional mean of the nominal shortterm (one-month) interest rate, and $\pi^{*}$ is the monetary authority's target level of inflation rate (set to zero in the calibration). $y_{t}$ is the output level. The potential output level, $\bar{y}_{t}$, is defined as

$$
\bar{y}_{t}=\psi y_{t}+(1-\psi) \bar{y}_{t-1}
$$

where $0<\psi<1$.

There are two major differences between equation (3.16) and the original Taylor rule. First, equation (3.16) includes a lagged short-term interest rate, aimed at capturing the monetary authority's tendency to smooth changes in interest rates, as argued by Woodford (2003). The monetary policy shock, $\varepsilon_{r, t}$ in equation (3.16), is assumed to be distributed as $N\left(0, \sigma_{r}^{2}\right)$. The shock can either be interpreted as randomness in the monetary authority's implementation of the monetary policy rule (such as an institutional randomness), or, if we are willing to assume that the monetary authority has an information advantage over private agents and is able to respond to some variables that it observes but that private agents do not, then $\varepsilon_{r, t}$ 's can also represent the variables observed only by monetary authority but not by the public. The shock $\varepsilon_{r, t}$ is, in addition, uncorrelated with the technology shock $\varepsilon_{A, t}$ at all leads and lags.

The second major difference between equation (3.16) and the original Taylor rule is the interpretation of the output gap. In Taylor's original formulation and in many descriptions of optimal monetary policy, the output gap is interpreted as the difference between actual outuput and a flexible-price output, where the latter is conditional on the current levels of all state variables other than the price level. However, in reality the Federal Reserve is unable to observe or accurately estimate a flexible-price output in real time, but rather may rely on some linear rule to update its estimates of potential output or the natural rate of unemployment (Orphanides and Williams (2002)). Equation (3.17) assumes such a simple learning rule for the monetary authority. Notice that when $\psi$ is set to zero, the output gap will be defined as the deviation of actual output from a deterministic trend or steady-state output, as in Rotemberg and Woodford (1997) and Basu and Kimball (2004).

Finally, the government creates fiat money and imposes lump-sum taxes, $\tau_{t}$, on households. Its budget constraint is in the following form: 


$$
\frac{M_{t}-M_{t-1}}{P_{t}}+\tau_{t}=0
$$

In order to maintain money market equilibrium, the money supply adjusts endogenously to meet the money demand at short-term interest rates set by the monetary authority. Therefore the policy at equilibrium will be characterized by a combination of an "active" monetary policy and a "passive" fiscal policy, as in Sims (1994).

\section{Affine Term Structure with Macro Factors}

The general equilibrium model developed in Section 3 does not possess an analytical solution. Conventional numerical methods are hardly applicable here because of the heavy computational burden required to solve such a large-scale model. Most dynamic stochastic general equilibrium models in the macroeconomics literature are solved by various linearization methods. However, linearizing rational expectations models generates "certainty equivalence" in the model solution, which implies that agents would behave as if they were risk-neutral. Consequently, different kinds of assets would have identical expected rates of return, and this makes the task of pricing assets trivial.

This section develops a tractable algorithm to overcome this dilemma. It solves the model using the loglinear-lognormal approximations as first proposed by Jermann (1998), and the interest rates of different maturities turn out to be linear functions of the state variables from the underlying general equilibrium model. The algorithm preserves the simplicity of linearization methods while avoiding "certainty equivalence" by deriving the term structure of interest rates along the standard asset-pricing approach. Although in this paper I focus on examining the term structure behavior in the specific model laid out earlier, the algorithm can be applied to other kinds of dynamic stochastic general equilibrium models as well.

The first step of the algorithm is to loglinearize the Euler equations of the general equilibrium model (see the Appendix for details) around the non-stochastic steady state and solve the resulting system of linear difference equations. The model solution of the variables $z_{t}$ is in linear functions of the state variable $s_{t}$

$$
z_{t}=\mu_{z}+\Psi_{z} s_{t}
$$

with the law of motion of $s_{t}$ given by 


$$
s_{t}=\mu_{s}+\Psi_{s} s_{t-1}+\Sigma_{s} \varepsilon_{t}
$$

where $\varepsilon_{t}=\left(\varepsilon_{r, t}, \varepsilon_{A, t}\right)^{\prime}$ are the structural shocks in the model economy.

The Euler equations for pricing the nominal bonds are

$$
b_{j, t}=\beta E_{t}\left(\frac{\lambda_{t+1} / P_{t+1}}{\lambda_{t} / P_{t}} b_{j-1, t+1}\right)=E_{t}\left(S D F_{t+1} b_{j-1, t+1}\right) \quad j=1,2, \ldots, J
$$

where $b_{j, t}$ is the price of $j$-period nominal zero-coupon bonds at time $t . \lambda_{t}$ is the Lagrangian multiplier of the agent's monetary budget constraint (3.1), and $P_{t}$ is the general price level. $S D F_{t+1}$ is the stochastic discount factor for nominal assets and is defined as

$$
S D F_{t+1}=\beta \frac{\lambda_{t+1} / P_{t+1}}{\lambda_{t} / P_{t}},
$$

and its dynamics are obtained from equation (4.1) as

$$
\ln \left(S D F_{t+1}\right)=\alpha_{0}+\alpha_{1}^{\prime} s_{t}+\alpha_{2}^{\prime} \varepsilon_{t+1}
$$

where $\alpha_{0}, \alpha_{1}$, and $\alpha_{2}$ are constants from $\mu_{z}, \Psi_{z} s_{t-1}$, and $\Sigma_{z}$.

Following the common practice in the asset-pricing literature, I then take the logarithm of equation (4.3):

$$
\begin{aligned}
\ln \left(b_{j, t}\right) & =E_{t}\left[\ln \left(S D F_{t+1}\right)+\ln \left(b_{j-1, t+1}\right)\right]+\frac{1}{2} \operatorname{var}_{t}\left[\ln \left(S D F_{t+1}\right)+\ln \left(b_{j-1, t+1}\right)\right] . \\
j & =1,2, \ldots, J
\end{aligned}
$$

Equation (4.6) holds exactly when the conditional distribution of bond prices, $b_{j, t+1}$, and the stochastic discount factor, $S D F_{t+1}$, are joint lognormal, or approximately if it is not (Campbell, Lo, and MacKinlay (1997)).

By substituting (4.5) into (4.6) for $j=1$ and noting that $b_{0, t}=1$, I obtain the following formula for a one-period bond rate:

$$
\begin{aligned}
-r_{1, t} & =\ln \left(b_{1, t}\right)=E_{t}\left[\ln \left(S D F_{t+1}\right)\right]+\frac{1}{2} \operatorname{var}_{t}\left[\ln \left(S D F_{t+1}\right)\right] \\
& =\alpha_{0}+\alpha_{1}^{\prime} s_{t}+\frac{1}{2} \alpha_{2}^{\prime} \alpha_{2}
\end{aligned}
$$


Note that if we simply loglinearize all the Euler equations, the one-month short rate would be $-\alpha_{0}-\alpha_{1}^{\prime} s_{t}$, differing from equation (4.7) by $\alpha_{2}^{\prime} \alpha_{2} / 2$. This occurs because the loglinearization algorithm ignores the agent's considerations about uncertainties and throws away the risk compensations. The lognormality formula in equation (4.6) picks up this risk-compensation term and yields the risk-rectified one-month rate.

Equations (4.5) and (4.6) also imply that the market price of the risks associated with the fundamental macro shocks, $\varepsilon_{t+1}$, is $-\alpha_{2}^{\prime}$. To see this, suppose that the $j$-period nominal bond carries $\gamma$ units of risks, so the logarithm of the price of a $j-1$ period nominal bond is

$$
\ln \left(b_{j-1, t+1}\right)=E_{t} \ln \left(b_{j-1, t+1}\right)+\gamma^{\prime} \varepsilon_{t+1}
$$

Substituting it back into equation (4.6) yields

$$
\ln \left(b_{j, t}\right)=-r_{1, t}+E_{t} \ln \left(b_{j-1, t+1}\right)+\alpha_{2}^{\prime} \gamma+\gamma^{\prime} \gamma / 2
$$

and the excess holding-period return of a $j$-period bond over a one-period bond becomes

$$
E_{t} \ln \left(b_{j-1, t+1}\right)-\ln \left(b_{j, t}\right)-r_{1, t}=-\alpha_{2}^{\prime} \gamma-\gamma^{\prime} \gamma / 2
$$

where $-\gamma^{\prime} \gamma / 2$ appears because of the convexity effect and is negligible, and $-\alpha_{2}^{\prime} \gamma$ is the compensation for carrying $\gamma$ unit of risks. Therefore, $-\alpha_{2}^{\prime}$ is the market price of risks associated with the macro shocks $\epsilon_{t}$ 's.

The state transition equation (4.2), the short-rate equation (4.7) and the risk-price solution $-\alpha_{2}^{\prime}$ form a discrete-time Gaussian affine term structure model. It falls within the class of affine term structure models since the logarithm of the bond prices is a system of linear (or affine) functions of the state variables $s_{t}$. More precisely, the formulae of the logarithm of the bond prices are given by

$$
\ln \left(b_{j, t}\right)=\bar{A}_{j}+\bar{B}_{j}^{\prime} s_{t}
$$

and the coefficients $\bar{A}_{j}$ and $\bar{B}_{j}$ are recursively defined by

$$
\begin{aligned}
\bar{A}_{1} & =\alpha_{0}+\frac{1}{2} \alpha_{2}^{\prime} \alpha_{2} \\
\bar{B}_{1} & =\alpha_{1} \\
\bar{A}_{j+1}-\bar{A}_{j} & =\bar{B}_{j}^{\prime}\left(\mu_{s}+\Sigma_{s} \alpha_{2}\right)+\frac{1}{2} \bar{B}_{j}^{\prime} \Sigma_{s} \Sigma_{s}^{\prime} \bar{B}_{j}+\bar{A}_{1} \\
\bar{B}_{j+1} & =\Psi_{s}^{\prime} \bar{B}_{j}+\bar{B}_{1} ; \quad j=1,2, \ldots, J
\end{aligned}
$$


The continuously compounded yield to maturity, $r_{j, t}$, of a $j$-period nominal zero-coupon bond is then given by

$$
r_{j, t}=-\ln \left(b_{j, t}\right) / j=A_{j}+B_{j} s_{t} .
$$

where $A_{j}=-\bar{A}_{j} / j$ and $B_{j}=-\bar{B}_{j} / j .{ }^{6}$

The Gaussian affine term structure model established above appears similar to those in Vasicek (1977), Duffie and Kan (1996), Dai and Singleton (2000), Ang and Piazzesi (2003), Rudebusch and $\mathrm{Wu}$ (2004), and others. However, this model is different in several ways. In this model, both the dynamics of state variables and those of the term structure are endogenously derived from a rational expectations general equilibrium model, and all the factors have clear macroeconomic interpretations. In contrast, most of the term structure models in the finance literature view term structure movement as controlled by some unobservable latent factors whose stochastic processes are exogenously given. Recent studies such as Ang and Piazzesi (2003) and Ang and Piazzesi and Wei (2004) include real GDP growth and the inflation rate as additional macro factors in their latent-factor models, but the underlying state dynamics are still in reduced forms, and the latent term structure factors still lack clear macro significance. Hördahl, Tristani, and Vestin (2004) and Rudebusch and Wu (2004) build their term structure models on top of a reduced-form New Keynesian model, and Rudebusch and Wu (2004a) further provide macro interpretations of the latent term structure factors. However none of these affine term structure models are based on a dynamic stochastic general equilibrium model. Furthermore, the market price of risks in this model is obtained as part of the macro general equilibrium solution. In contrast, the above studies only assume a flexible functional form of risk prices and estimate them. Although the risk price representations adopted by those studies prove to be quite effective in matching certain properties of the U.S. term structure such as explaining the deviations from the expectations hypothesis (Dai and Singleton (2002)), they still lack concrete equilibrium interpretations. As pointed out by Cox, Ingersoll, and Ross (1985) and Longstaff and Schwartz (1992), arbitrarily choosing a functional form of risk compensation may lead to internal inconsistency or arbitrage opportunities. The general equilibrium approach adopted in

\footnotetext{
${ }^{6}$ Although the real term structure is not focused on here, it can be easily derived in a similar fashion. With the real pricing kernel defined as $S D F_{t+1}^{R}=\beta \lambda_{t+1 t} / \lambda_{t}$ and $\ln \left(S D F_{t+1}^{R}\right)=\alpha_{0}^{R}+\alpha_{1}^{R \prime} s_{t}+\alpha_{2}^{R \prime} \varepsilon_{t+1}$, the real oneperiod interest rate becomes $r_{1, t}^{R}=-\ln \left(b_{1, t}^{R}\right)=-\alpha_{0}^{R}-\alpha_{1}^{R \prime} s_{t}-\frac{1}{2} \alpha_{2}^{R \prime} \alpha_{2}^{R}$; real long-term real interest rates can be calculated in a formula similar to equation (4.10).
} 
this paper clearly has advantages over the reduced-form studies in this dimension.

However, such advantages come at a price. In particular, by taking lognormality approximations of Euler equations in such a Gaussian general equilibrium model with constant variances, I am essentially restricting the pricing kernel to be conditional homoskedastic (equation (4.5)). This leads to constant term premia and implies an expectations hypothesis, which is largely rejected by post-war U.S. data in most empirical studies (although several recent studies, including Lange, Sack, and Whitesell (2003) and Rudebusch and Wu (2004b), find that the behavior of the expectations hypothesis since the mid-1980s has improved greatly). However, as I show in the next section, this approximation does not hurt the model's ability to replicate salient business cycle patterns of the term structure movement, which is the focus of this study.

\section{Calibration of the Macro Affine Term Structure Model}

This section calibrates the sticky-price model and compares the model implications for joint macro-term structure movement with the VAR estimation results from Section 2. Based on model calibration and simulations, I also investigate the economic nature of the latent term structure factors as found in the finance literature.

\subsection{Model Calibration}

Table 1 reports the calibrated value of model parameters. I adhere closely to the general equilibrium business cycle literature in choosing these values. The discount factor $\beta$ is set equal to $(0.97)^{12}$. The range of possible relative risk-aversion parameter values, $\phi$, is quite wide in the literature, from 1 as in log utility to 11 as assumed by den Haan (1995). I choose to set it at 6, the midpoint between 1 and 11, which is also close to the 5.65 estimate of Leeper and Sims (1994) and between the two estimates reported by Epstein and Zin (2001), 4.82 and 8.21. The weight of consumption in the utility function $\gamma$ is calibrated to 0.6 as estimated in Leeper and Sims (1994). Kim (2000) reported a similar estimate of 0.67 . $\theta$ is set to 0.01 , which implies a transaction cost of about $0.7 \%$ of gross consumption as estimated by Leeper and Sims (1994).

For the production and firm side, the values of $\alpha$ (capital's share in the Cobb-Douglas production technology) and $\delta$ (the monthly capital depreciation rate) are standard choices. Following Rotemberg and Woodford (1995), the markup parameter $\mu$ is set to 1.4, the value also

chosen by Ireland (1997). The calibrated value of $\chi_{K}$, the parameter of the adjustment costs of 
capital investment, is calibrated to Kim (2000)'s estimate, implying capital adjustment costs of $5.6 \%$ of gross investment at steady state. The value of $\chi_{P}$ (the parameter of adjustment cost of changing the prices) is set to 4 , implying that in steady state the adjustment costs of changing the prices by $10 \%$ (or $120 \%$ if expressed in annual rates) in excess of the long-run inflation rate are about $2 \%$ of the total output. Ireland (1997) reports a similar estimate of $\chi_{P}$ at 4.05 .

For the monetary policy rule, $\theta_{1}$ and $\theta_{2}$ are set to the original values suggested by Taylor (1993). Potential output is assumed to be a mixture of last period's potential output and this period's real output, with each accounting for $50 \%$ of the potential output level for this period. The autoregressive coefficient in the monetary policy rule, $\rho_{r}$, is set to 0.95 , corresponding to a quarterly interest-smoothing parameter of about 0.86 , close to various estimates (e.g., Clarida, Galí and Gertler (2000)) of the Federal Reserve's policy rule.

Finally, the technology is assumed to follow a quite persistent process, with the AR(1) coefficient $\rho_{A}$ set at 0.99 , or about 0.97 on a quarterly frequency, which is the estimate obtained by Ireland (1997). Kim (2000) reports an even higher estimate of 0.98, and Leeper and Sims (1994) obtains an estimate of almost unit root (both on quarterly frequency). $\sigma_{r}$ (the standard deviation the monetary policy shocks) is set at 50 basis points (annual rate), and $\sigma_{A}$ is set to 0.0087, as implied by den Haan (1995) and close to Ireland (1997). As I show below, such choices of the sizes of shocks imply impulse responses that are similar in magnitude to the empirical VAR estimation results.

\subsection{Implications of Model Calibration}

\subsubsection{Model Implications on the Macro Economy}

To understand the response of the term structure to macroeconomic structural shocks, it is useful first to look into the dynamics of output, consumption, investment, and inflation in the model. Figure 3 plots the impulse responses of various macroeconomic aggregates to a onestandard-deviation increase in each of the two structural shocks in the model. Each response is measured in percentage point deviations from the steady state.

The first column of Figure 3 shows the impulse responses to a one-standard deviation contractionary monetary policy shock. Such a shock leads to an instant 26-basis point increase in the nominal 1-month interest rate (annualized), and the price level declines by $0.2 \%$. The monetary contraction lowers output by $0.1 \%$ and consumption and employment by $0.2 \%$. The 
declines in the levels of both inflation and output cause a gradual easing of monetary policy, and both inflation and output return to their original levels in about five months. This implies that the monetary policy shock has a significant but transitory effect in the calibrated model. Investment is virtually unchanged, as it is too costly to adjust capital stocks in response to a transitory shock. By and large, the model replicates the dynamic responses of the macro aggregates as observed in the VAR estimation. However, the monetary policy shock has a longer-lasting effect on output in the VAR estimation than in the calibrated model. This is not surprising, as the literature has concluded that it is very difficult for rational expectations models to generate any long-lasting effects on output or long-term interest rates (Gürkaynak, Sack, and Swanson (2004)). Increasing the price-stickiness parameter, $\chi_{P}$, will help prolong monetary policy's real effects, but not enough to match the persistence observed in the VAR estimation.

The second column of Figure 3 displays the impulse responses to a one-standard deviation positive technology shock, which increases output by about $1 \%$. The shock strongly boosts capital investment and employment, and consumption jumps by about $0.5 \%$ and continues to increase. Higher productivity tends to lower the price level slightly, and this partly offsets the central bank's intention to raise the interest rate in the face of a positive output gap. Consequently the nominal one-month rate gradually rises, with a maximal increase of 13 basis points. The impulse responses in this column are still significantly different from zero two years after the initial shock, as the technology shocks are quite persistent in the calibrated model. This is consistent with the empirical findings in the VAR estimation.

The fact that the monetary policy shocks appear transitory and that technology shocks appear permanent in this model does not depend on the relative sizes of $\rho_{r}$ and $\rho_{A}$. Indeed, when $\rho_{r}$ is set to 0.99 and $\rho_{A}$ to 0.9 (or about 0.72 on a quarterly frequency, which is much lower than the estimates obtained in the previous literature), the output response to the monetary policy shocks still dissipates away in less than one year, while the response to the technology shock remains above zero even two years after the initial shock. This is consistent with other dynamic stochastic general equilibrium studies which find that monetary policy shocks have transitory real effects, while technology shocks have persistent real effects.

\subsubsection{Model Implications on the Term Structure}

Risk Compensations on Nominal and Real Assets 
The market prices of macro uncertainties implied by the parameter calibration are given in Table 2. As equation (4.8) indicates, the risk prices reported are indeed the excess risk premium or excess holding-period return (in excess of the default-free 1-month interest rate) on any financial asset that carries one unit of macroeconomic structural shocks. In particular, in the benchmark calibration case (Table 1), a nominal asset carrying one unit of risk associated with contractionary monetary policy shocks calls for a risk premium of $-0.57 \%$ (monthly), or about $7 \%$ per annum, and a nominal asset carrying one unit of risk associated with positive technology shocks requires a risk premium of $1.44 \%$ (monthly), or $17 \%$ per annum. On the other hand, if returns are denominated in real terms, then a real asset loaded with one unit of risk associated with contractionary monetary policy shocks will have a negative excess return of $4 \%$ (annualized, over 1-month real bond), and if the real asset instead carries one unit of risk associated with positive technology shocks, then the expected excess return on this asset in one year will be $18 \%$.

The reason for a negative risk premium on carrying contractionary monetary policy shocks is as follows: in the model economy, a contractionary monetary policy shock decreases the levels of output and consumption, as shown in the first column of Figure 3. If an asset yield is high when the monetary contraction occurs and low when the monetary expansion occurs, then holding such an asset tends to mitigate the consumption variability compared with holding the risk-free asset. The investors in the model economy are willing to hold such an asset even if its expected return is lower than the risk-free short rate; that is, such an asset will have a negative risk premium.

On the other hand, a positive technology shock boosts levels of the output and consumption. As the marginal utility of consumption becomes lower, the asset returns are valued less. Therefore, an asset whose returns are positively correlated with the technology shock needs to have a higher expected rate of return than the risk-free rate to compensate the investors for holding it. Consequently, this asset asks for a positive risk premium.

The rest of Table 2 reveals some interesting relations between risk prices and certain properties of the model. For instance, a higher (lower) risk aversion parameter $\phi$ increases (decreases) the magnitude of risk prices, as more (less) risk-averse agents will require higher (lower) compensation for carrying the same risks. However, changes in the risk price of technology shocks are much larger than changes in the risk price of monetary policy shocks, as the technology 
shocks have much larger effects on consumption, and, therefore on the intertemporal marginal rate of substitution (IMRS).

In the absence of price stickiness, monetary policy shocks have very little effect on consumption and employment and, therefore, on the IMRS. Thus the associated risk compensation for a real asset is almost zero (row 5 of Table 2). The risk compensation for technology shocks, on the other hand, is slightly higher, as output and employment will respond more strongly to a technology shock in a flexible-price economy than in a sticky-price economy. The risk premia on nominal assets, however, are almost the same as in the sticky-price economy, as the increases in the volatility of the price level are partly offset by the decrease in the volatility of consumption (equation (4.4)).

Finally, without capital adjustment $\operatorname{costs}\left(\chi_{K}=0\right)$, a positive technology shock leads to a stronger increase in investment and a weaker increase in consumption. Thus the IMRS becomes slightly less volatile and the associated risk price declines (row 6 of Table 2). The impulse responses of consumption to monetary policy shocks, however, are very similar to those with nonzero capital adjustment costs, and thus the associated risk price is unchanged.

\section{Impulse Responses of the Term Structure to Structural Shocks}

Figure 4 displays the instantaneous impulse responses of the term structure to the two macroeconomic shocks in the model. A one-standard-deviation contractionary monetary policy shock raises the 1-month interest rate by about 26 basis points, much more than long-term interest rates (about 1 basis point at 5-year maturity). Thus the yield curve tilts and becomes less steeply upward-sloped (or more steeply downward-sloped). This resembles the effect of a "slope" factor movement as identified in numerous term structure studies (e.g., Litterman and Scheinkman 1991 and Knez, Litterman, and Scheinkman 1994). On the other hand, a onestandard-deviation positive shock to technology raises the yields of all maturities by much more similar amounts: 8 basis points for the 1-month maturity, 12 basis points for the 1-year maturity, and 5 basis points for the 5 -year maturity. It thus boosts the level of the entire yield curve and is quite similar to the impact of a "level" factor as found in the finance literature.

Next consider the model dynamics for the term structure more generally. As displayed in the first column of Figure 5, a one-standard-deviation contractionary monetary policy shock raises the 1-month interest rate by approximately 26 basis points; the response declines rapidly, and six months after the shock, the rate returns to its steady-state level. Longer-term interest rates 
display qualitatively similar but quantitatively smaller responses: the 3-month interest rate rises by 15 basis points and it returns to within 1 basis point of its steady-state level in five months; the 1-year, 2-year and 5-year rates increase by 5, 2, and 1 basis points on impact, and the responses die away in three to four months. Therefore, a contractionary monetary policy shock has transitory effects on the term structure and causes the yield curve to flatten (the "slope" decreases by 25 basis points within the month of shock, and does not return to its original level for six months).

On the other hand, a one-standard deviation positive technology shock raises the interest rates of different maturities by similar amounts, both at impact and over time. The responses are persistent: even two years after the shock, bond rates with a maturity of two years or less are still significantly higher than their steady-state levels, and the 5-year bond rate returns to its steady state level only after eighteen months. Such changes lead to a very persistent, almost parallel, upward shift of the whole yield curve on impact (the "level" jumps up by 9 basis points on the shock), but have a negligible effect on the slope of the yield curve ("slope" decreases by 3 basis points within the first month of impact, much less than the 25 basis points in column 1).

In summary, the two kinds of structural shocks in the model have very different implications for the term structure: the monetary policy shocks affect the term structure primarily by changing its slope, and technology shocks affect the term structure by shifting its level. Moreover, the effects of technology shocks on the term structure are much more persistent than those of monetary policy shocks. These patterns are both qualitatively and quantitatively similar to those obtained from the VAR study.

\subsection{Identifying the Term Structure Factors}

Most of the term structure studies in the finance literature characterize term structure movement as controlled by some latent factors, often called "level," "slope," "curvature," etc (Knez, Litterman and Scheinkman (1994)), without assigning macroeconomic significance to them. The impulse responses shown in Figures 4 and 5 suggest close links between monetary policy shocks and the slope of the yield curve, and between technology shocks and the level of the yield curve. This subsection further explores these links. For parsimony I continue to use the intuitive definition of "level" and "slope" used above instead of any model-specific definition used in various empirical term structure studies, such as Vasicek (1977), Dai and Singleton (2000) or Ang and 
Piazzesi (2003), etc.

First, examine the variance decompositions displayed in Table 3 . Columns 2 to 5 of the table report the variance decompositions as implied by the model calibration in the benchmark case, and columns 6 to 9 report the variance decompositions from the VAR estimation in Section 2. In the calibrated model, monetary policy shocks have strong influences on the short end of the yield curve, but much weaker effects on the long end: these shocks account for $56 \%$ and $32 \%$ of the conditional variances of the 1-month rate at one-month and three-month forecasting horizons, but only $13 \%$ for the 5 -year rate at the three-month horizon. Consequently monetary policy shocks account for most of the variability of the "slope" of the yield curve (76\% at 1month horizon) but only a small fraction for the variability of the "level" (19\% at the one-month horizon). Such effects decline sharply as the forecasting horizon lengthens, and at the one-year horizon only $12 \%$ of the conditional variances of the 1 -month rate and $18 \%$ of the conditional variances of the "slope" are attributable to monetary policy shocks, with much smaller fractions for the 5-year rate and the "level" factor.

In contrast, the technology shocks account for a smaller fraction of the conditional variances of the short end of the yield curve and the "slope," especially at short forecasting horizons. However, these shocks are responsible for most of the variability of the long end of the yield curve as well as the "level": $87 \%$ for the 5-year rate at the three-month horizon, $81 \%$ for the "level" at the one-month horizon, and $91 \%$ at the three-month horizon. Moreover, as the forecasting horizon lengthens, the technology shocks start to dominate the movement of the whole yield curve: at the one-year horizon, $97 \%$ of the conditional variances of the "level" and $82 \%$ of the "slope" are attributable to the technology shocks. And these fractions are even higher at the two-year horizon.

The VAR estimation results also reveal similar patterns: ${ }^{7}$ the monetary policy (FFR) shocks account for the majority of the conditional variances of the short end of the yield curve at short forecasting horizons, but only a small fraction of the conditional variances of the long end of the yield curve ( $7 \%$ for 5 -year rate at the one-month horizon). They explain a substantial part of the "slope" movement (31\% at the one-year horizon) but much less of the "level" (11\% at the oneyear horizon). Moreover, such effects decline substantially as the forecasting horizon lengthens.

\footnotetext{
${ }^{7}$ It should be noted that the monetary policy shocks and the technology shocks are the only two kinds of shocks in the calibrated model, while in the VAR there are five additional kinds of shocks. Consequently the sizes of the fractions reported in columns 6 to 9 are expected to be much smaller than their counterparts in columns 2 to 5 .
} 
On the other hand, compared with the monetary policy shocks, the output (IP) shocks explain a larger portion of the bond rate movements at the long end of the yield curve $(13 \%$ versus $7 \%$ at the one-month horizon and $13 \%$ versus $4 \%$ at the one-year horizon for 5 -year rate), but at the short end of the yield curve the pattern is reversed (6\% versus $57 \%$ at the one-month horizon and $19 \%$ versus $34 \%$ at the one-year horizon for 1-month rate). In terms of the transmission channels on the whole yield curve, output shocks tend to change the "level" rather than the "slope", as they explain a much higher fraction of "level" movement than "slope" movement (14\% versus $9 \%$ at one-month horizon and $19 \%$ versus $6 \%$ at one-year horizon). And there is no significant declining trend for such effects as the forecasting horizon lengthens, indicating that output shocks are relatively more persistent than monetary policy shocks.

In summary, the variance decompositions from both the model calibration and the empirical VAR estimation support our conjecture that technology shocks play an important role in driving the movement of the "level" factor as found in the term structure literature, and the exogenous monetary policy shocks are closely related to the "slope" factor of the term structure.

Next I perform a simulation study to provide more supporting evidence for these interpretations. I simulate the calibrated model as well as the whole yield curve (all 60 maturities from 1-month to 5-year) based on equations (4.10) and (4.11), and then regress the changes in the implied term structure factors "level" and "slope" on current and lagged simulated monetary policy shocks. Table 4 displays the median as well as $90 \%$ frequency or confidence bands of the regression coefficients based on 1000 simulation draws, with each draw 300 months long.

In simulations based on the benchmark calibration (columns 2 and 3), the monetary policy shocks have little effect on the movement of the "level," with an adjusted $R^{2}$ of 0.17 . However, these shocks have strong effects on the "slope" factor: one unit of a monetary policy shock decreases the "slope" factor by 25 basis points in the month of the shock before the "slope" factor gradually returns to its original level. A total of $94 \%$ of the variations of the changes in the "slope" are attributable to the current and lagged monetary policy shocks in the past three months. Notice that because technology shocks are the only other kind of shocks in the model, most of the unexplained variations in the regression equations are attributable to them; in other words, the technology shocks explain most of the variations of the changes in the "level" factor but little of the "slope" movement.

Changing the relative persistence of these two kinds of shocks will certainly affect the inter- 
pretations of the term structure factors. Columns 4 and 5 shows the simulation results when the monetary policy instrument (1-month rate) is assumed to be a very persistent process $\left(\rho_{r}=0.99\right)$ and technology shocks a less persistent one $\left(\rho_{A}=0.95\right)$. When the short-term interest rate becomes a near random walk, a change in the short rate will cause quantitatively similar changes in expected future short rates. Such a change will have a substantial impact on long-term interest rates and essentially shift up the level of the whole yield curve; as a result, monetary policy shocks now explain a larger part of the "level" movement (but still much less than the portion explained by technology shocks in the benchmark case). On the other hand, monetary policy shocks still explain most of the movement of the "slope" factor, as long-term rates respond by less than short-term rates when monetary policy shocks occur. This also indicates that technology shocks still affect the term structure by changing the "level" factor, even when the shocks become less persistent.

Rudebusch and $\mathrm{Wu}$ (2004a) formulate a joint macro-term structure model and interpret the "level" factor as the time-varying inflation target as perceived by the public and the "slope" factor as the cyclical responses of the Federal Reserve to deviations of inflation and output from its policy goals. For the "slope" factor, their interpretation is consistent with the interpretation implied in the model calibration and simulation exercise. For the "level" factor, the two interpretations seem rather different but, in fact, complement each other in the following sense: note that in the Taylor rule equation (3.16), the inflation target is set to a constant $\pi^{*}$ in this model. If I relax this assumption and introduce a persistent process for the inflation target (which is exactly what Rudebusch and Wu (2004a) find), this process will undoubtedly affect the interest rates of different maturities by similar amounts and thus dominate the "level" factor movement. ${ }^{8}$ On the other hand, Rudebusch and Wu (2004a) assume a constant long-term real interest rate, which is not constant in this model — as shown in Figures 3 and 5, technology shocks have very persistent effects on employment and capital accumulation and, consequently, on the long-term real interest rates and the "level" factor. One can imagine that if Rudebusch and $\mathrm{Wu}(2004 \mathrm{a})$ have a persistent long-term real rate in their model, it would play an important role in determining the "level" factor. Thus, although the differences in modeling assumptions in these two studies lead to different interpretations of the "level" factor, they simply present different facades of the identity of the "level" factor and, indeed, complement each other.

\footnotetext{
${ }^{8}$ The introduction of a very persistent process $\pi_{t}^{*}$ will increase the persistence of the nominal short rate, and as shown in column 4 of Table 4 , this will greatly increase the $R^{2}$ of the "level" factor regression.
} 


\section{Concluding Remarks}

This paper develops a joint macro-term structure framework that allows one to derive an affine term structure model of bond yields from a large class of general equilibrium business cycle models with complete markets. This framework facilitates analyzing the joint dynamics of the macroeconomy and the term structure of interest rates and exploring the mechanism through which fundamental macroeconomic shocks affect the term structure. This is part of a rapidly growing effort to connect the general equilibrium business cycle literature in macroeconomics with the term structure literature in finance by providing an explanation of the cyclical behavior of the term structure along the general equilibrium approach.

I also find that a simple dynamic stochastic general equilibrium model, in which the nominal rigidities take the form of quadratic price adjustment costs in the monopolistically competitive commodity market, perform fairly well in replicating the empirical cyclical pattern of the term structure movement. Moreover, the model provides theoretical interpretations of the latent term structure factors found in the finance literature: most of the "slope" factor movement can be explained by exogenous monetary policy shocks, and the "level" factor movement is closely related to technology shocks.

I conclude by noting a few avenues for future research. First, a number of studies suggest that the monetary authority may have a time-varying, persistent inflation target. This model can be easily extended to examine the implications of such an inflation target for the term structure. Second, the state-dependent, linear risk price representations adopted by many recent Gaussian affine term structure studies prove to be quite effective in generating time-varying term premia and matching certain properties of the U.S. term structure movement (Duffee (2002), Dai and Singleton (2002), Ang and Piazzesi (2003), etc). However, they are simply statistical representations, and it is still a challenge to justify them in a general equilibrium setting. Finally, the model established in this paper assumes the existence of a complete financial market. It would be of interest to incorporate various kinds of financial frictions into the standard businesscycle models and study the implications that follow, in particular on the term premia. 


\section{References}

[1] Ang, Andrew and Monika Piazzesi, 2003. "A No-Arbitrage Vector Autoregression of Term Structure Dynamics with Macroeconomic and Latent Variables," Journal of Monetary Economics, 50, 745-787.

[2] Ang, Andrew, Monika Piazzesi, and Min Wei (2004), "What does the Yield Curve Tell us about GDP Growth?" Journal of Econometrics, forthcoming.

[3] Basu, Susanto, and Miles Kimball, 2004. "Investment Planning Costs and the Effects of Fiscal and Monetary Policy," working paper, University of Michigan.

[4] Bernanke, B. and Blinder, A., 1992. "The Federal Funds Rate and the Channels of Monetary Transmission", American Economic Review, 82, 901-921.

[5] Blanchard, O. and Kiyotaki, N., 1987. "Monopolistic Competition and the Effects of Aggregate Demand", American Economic Review, 77, 647-666.

[6] Calvo, G. A., 1983. "Staggered Prices in a Utility-Maximizing Framework", Journal of Monetary Economics, 12, 383-398.

[7] Campbell, John Y., Andrew W. Lo, and A. Craig MacKinlay, 1997. "The Econometrics of Financial Markets," Princeton University Press.

[8] Chapman, David A., 1997. "The Cyclical Properties of Consumption Growth and the Real Term Structure," Journal of Monetary Economics, 39, 145-172.

[9] Clarida, Richard, Jordi Galí, and Mark Gertler (2000), "Monetary Policy Rules and Macroeconomic Stability: Evidence and Some Theory," Quarterly Journal of Economics 115, $147-180$.

[10] Constantinides, G. M., 1992. "A Theory of the Nominal Term Structure of Interest Rates", Review of Financial Studies, 5 (4), 531-552.

[11] Cox, J. C., J. E. Ingersoll, and S. A. Ross, 1985, "A theory of the term structure of interest rates", Econometrica, 53, 385-407.

[12] Dai, Q. and K.J. Singleton (2000), "Specification Analysis of Affine Term Structure Models," Journal of Finance 55, 1943-1978. 
[13] Dai, Q. and K.J. Singleton (2002), "Expectations puzzles, time-varying risk premia, and affine models of the term structure," Journal of Financial Economics 63, 415-441.

[14] den Haan, W. J., 1995. "The Term Structure of Interest Rates in Real and Monetary Economies", Journal of Economic Dynamics and Control, 19, 909-940.

[15] Dewachter, H. and M. Lyrio (2002), "Macro Factors and the Term Structure of Interest Rates," manuscript, Catholic University of Leuven.

[16] Duffie, D. and R. Kan (1996), "A Yield-Factor Model of Interest Rates," Mathematical Finance 6, 379-406.

[17] Duffee, G.R. (2002), "Term Premia and Interest Rate Forecasts in Affine Models," Journal of Finance 57, 405-443.

[18] Epstein, L.G., and S.E. Zin, 2001. "The Independence Axiom and Asset Returns," Journal of Empirical Finance, vol. 8, issue 5, 537-572.

[19] Estrella, A. and Hardouvelis, G., 1991. "The Term Structure as a Predictor of Real Economic Activity", Journal of Finance, 46, 555-576.

[20] Evans C. L. and D. A. Marshall, 1998. "Monetary Policy and the Term Structure of Nominal Interest Rates: Evidence and Theory", Carnegie-Rochester Conference Series on Public Policy, 49, 53-111.

[21] Gürkaynak, Refet S., Brian Sack, and Eric Swanson (2004), "The Excess Sensitivity of LongTerm Interest Rates: Evidence and Implications for Macroeconomic Models," American Economic Review, forthcoming.

[22] Hördahl, Peter, Oreste Tristani, and David Vestin (2004), "A Joint Econometric Model of Macroeconomic and Term Structure Dynamics," manuscript, European Central Bank, Journal of Econometrics, forthcoming.

[23] Ireland, Peter N., 1997. "A Small, Structural, Quarterly Model for Monetary Policy Evaluation", Carnegie-Rochester Conference Series on Public Policy, 47, 83-108.

[24] Jermann, Urban J., 1998. "Asset Pricing in Production Economies," Journal of Monetary Economics, 41, 257-275. 
[25] Kim, Jinill, 2000. "Constructing and Estimating a Realistic Optimizing Model of Monetary Policy", Journal of Monetary Economics, 45, 329-359.

[26] King, Robert G., and Mark W. Watson, 1996. "Money, Prices, Interest rates and the Business Cycle", Review of Economic and Statistics, 78(1), 35-53.

[27] Knez, P., Litterman, R., and J. A. Scheinkman, 1994. "Explorations into Factors Explaining Money Market Returns", Journal of Finance, 49, 1861-1882.

[28] Kozicki, Sharon and Peter Tinsley, 2001. "Shifting Endpoints in the Term Structure of Interest Rates," Journal of Monetary Economics, 47, 613-652.

[29] Lange, Joe, Brian Sack, and William Whitesell, 2003. "Anticipations of Monetary Policy in Financial Markets," Journal of Money, Credit, and Banking 35(6), 889-909.

[30] Leeper, Eric M. and Christopher A. Sims, 1994. "Toward a Modern Macroeconomic Model Usable for Policy Analysis," NBER Macroeconomics Annual, 1994, 81-118.

[31] Litterman, R., and J. A. Scheinkman, J., 1991. "Common Factors Affecting Bond Returns", Journal of Fixed Income Securities, 1, 54-61.

[32] Longstaff, F.A. and E.S. Schwartz, 1992. "Interest Rate Volatility and the Term Structure: A Two Factor General Equilibrium Model", Journal of Finance, 47 (4), 1252-1282.

[33] Mishkin, Frederic S., 1990. "The Information in the Longer Maturity Term Strucutre About Future Inflation", Quarterly Journal of Economics, 105 (3), 815-828

[34] Orphanides, Athanasios, and John Williams, 2002. "Robust Monetary Policy Rules with Unknown Natural Rates," Brookings Papers on Economic Activity, vol. 2, 2002.

[35] Rotemberg, Julio, 1982a, "Monopolistic Price Adjustment and Aggregate Output", Review of Economic Studies, 49, 517-531.

[36] —, 1982b, "Sticky Prices in the United States", Journal of Political Economy, 90, 11871211.

[37] — and Michale Woodford, (1995). "Dynamic General Equilibrium Models with Imperfectly Competitive Product Markets", in Cooley, T.F. (Ed.), Frontiers of Business Cycle Research, 294-330. Princeton University Press. 
[38] — and —, 1997. "An Optimization-based Econometric Framework for the Evaluation of Monetary Policy," NBER Macroeconomics Annual, volume 12, 297-346.

[39] Rudebusch, Glenn D., and Tao Wu, 2004a. "A Macro-Finance Model of the Term Structure, Monetary Policy, and the Economy," Federal Reserve Bank of San Francisco working paper, 2003-17.

[40] —, and Tao Wu, 2004b. "The Recent Shift in Term Structure Behavior from a No-Arbitrage Macro-Finance Perspective," Federal Reserve Bank of San Francisco working paper, 200425 .

[41] Sims, Christopher, 1992. "Interpreting the Macroeconomic Time Series Facts: The Effects of Monetary Policy," European Economic Review, 36, 975-1000.

[42] —, 1994. "A Simple Model for the Determination of the Price Level and the Interaction of Monetary and Fiscal Policy," Economic Theory, 4, 381-399.

[43] Sun, T., 1992, "Real and Nominal Interest Rates: A Discrete-Time Model and Its Continuous Time Limit", Review of Financial Studies, 5, 581-611.

[44] Taylor, John B., 1993. "Discretion versus Policy Rules in Practice," Carnegie-Rochester Conference Series on Public Policy 39, 195-214.

[45] Vasicek, O., 1977, "An Equilibrium Characterization of the Term Structure", Journal of Financial Economics, 5, 177-188.

[46] Woodford, Michael, 2003, "Optimal Interest-Rate Smoothing," Review of Economic Studies, $70,861-886$.

[47] Wu, Tao, 2003. "Stylized Facts on Nominal Term Structure and Business Cycles: An Empirical VAR study", Applied Economics, 35, 901-906. 
Table 1: Calibration of Parameter Values

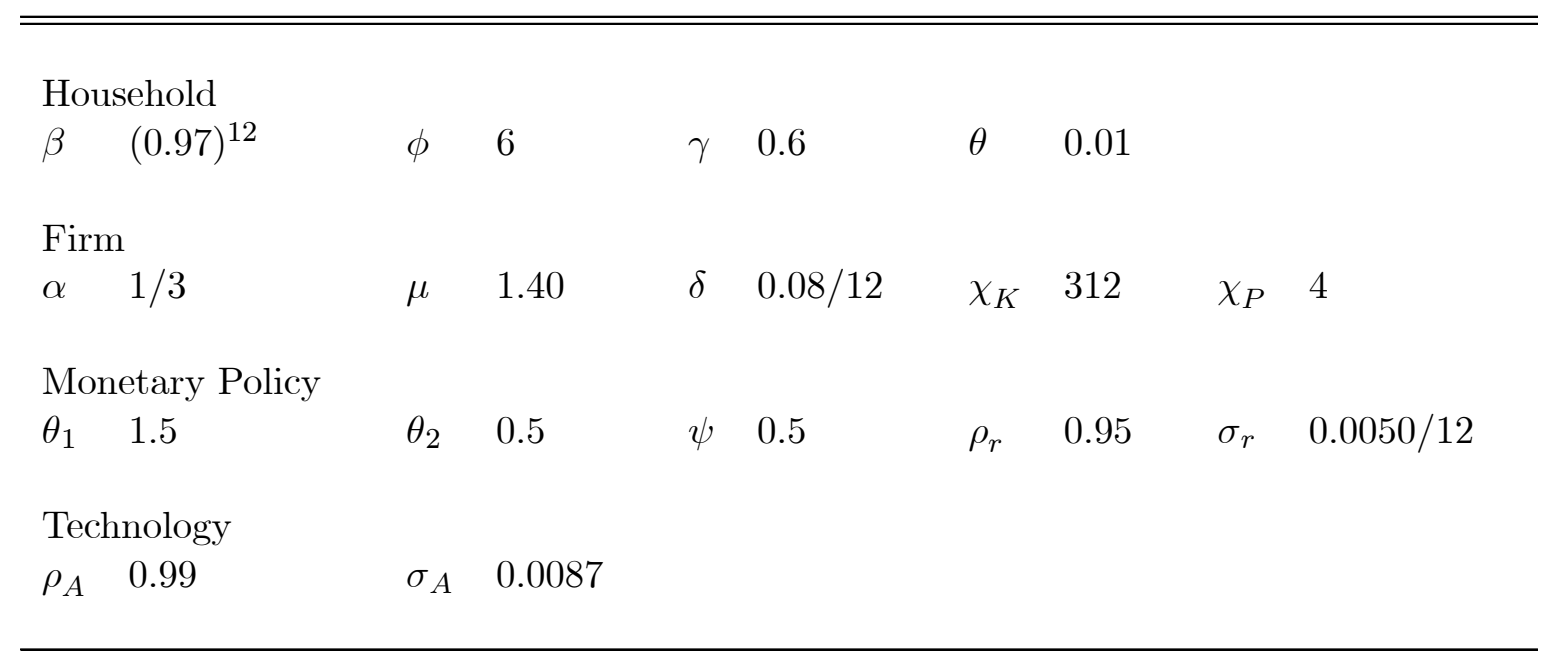


Table 2: Market Prices of Macroeconomic Risks

\begin{tabular}{l|ll|ll}
\hline Market price of risks & \multicolumn{2}{l|}{ Nominal Assets } & \multicolumn{2}{l}{ Real Assets } \\
\cline { 2 - 5 } & MP shock & Tech. shock & MP shock & Tech. shock \\
\hline Benchmark case (Table 1) & -0.0057 & 0.0144 & -0.0032 & 0.0152 \\
& & & \\
risk aversion $(\phi)$ & & & \\
$\phi=1$ & -0.0057 & 0.0024 & -0.0030 & 0.0033 \\
$\phi=11$ & -0.0058 & 0.0252 & -0.0033 & 0.0261 \\
frictions $\left(\chi_{P}, \chi_{K}\right)$ & & & & \\
$\chi_{P}=0, \chi_{K}=312$ & -0.0056 & 0.0144 & -0.00002 & 0.0162 \\
$\chi_{P}=4, \chi_{K}=0$ & -0.0057 & 0.0141 & -0.0032 & 0.0147 \\
$\chi_{P}=10, \chi_{K}=312$ & -0.0058 & 0.0144 & -0.0041 & 0.0149 \\
$\chi_{P}=4, \chi_{K}=3120$ & -0.0057 & 0.0160 & -0.0032 & 0.0180 \\
transaction costs $(\theta)$ & & & & \\
$\theta=0.1$ & -0.0058 & 0.0146 & -0.0033 & 0.0154 \\
\hline
\end{tabular}


Table 3: Variance Decompositions

\begin{tabular}{|c|c|c|c|c|c|c|c|c|}
\hline & $\begin{array}{l}\text { Model Calibration } \\
1-\mathrm{m}\end{array}$ & $5-y$ & level & slope & $\begin{array}{l}\text { VAR I } \\
1-\mathrm{m}\end{array}$ & istimat & level & slope \\
\hline $\begin{array}{l}\text { monetary policy shock } \\
\text { technology shock }\end{array}$ & $\begin{array}{l}\text { one-month horizon } \\
55.81 \\
44.19\end{array}$ & $\begin{array}{l}0.86 \\
99.14 \\
\end{array}$ & $\begin{array}{l}18.66 \\
81.34\end{array}$ & $\begin{array}{l}75.92 \\
24.08\end{array}$ & $\begin{array}{l}\text { one-m } \\
57.19 \\
6.49\end{array}$ & $\begin{array}{l}\text { nth ho } \\
7.36 \\
12.52\end{array}$ & $\begin{array}{l}\text { izon } \\
25.25 \\
14.25\end{array}$ & $\begin{array}{l}8.84 \\
9.18\end{array}$ \\
\hline $\begin{array}{l}\text { monetary policy shock } \\
\text { technology shock }\end{array}$ & $\begin{array}{l}\text { three-month horizor } \\
31.70 \\
68.30\end{array}$ & $\begin{array}{l}12.92 \\
87.08 \\
\end{array}$ & $\begin{array}{l}8.87 \\
91.13 \\
\end{array}$ & $\begin{array}{l}49.44 \\
50.56 \\
\end{array}$ & $\begin{array}{l}\text { three-1 } \\
62.20 \\
15.60\end{array}$ & $\begin{array}{l}\text { honth l } \\
4.32 \\
12.19\end{array}$ & $\begin{array}{l}\text { orizon } \\
23.85 \\
19.27\end{array}$ & $\begin{array}{l}19.29 \\
7.65\end{array}$ \\
\hline $\begin{array}{l}\text { monetary policy shock } \\
\text { technology shock }\end{array}$ & $\begin{array}{l}\text { one-year horizon } \\
11.50 \\
88.50\end{array}$ & $\begin{array}{l}0.19 \\
99.81\end{array}$ & $\begin{array}{l}3.05 \\
96.95\end{array}$ & $\begin{array}{l}17.79 \\
82.21\end{array}$ & $\begin{array}{l}\text { one-ye } \\
33.56 \\
19.49 \\
\end{array}$ & $\begin{array}{l}\text { ar horiz } \\
4.03 \\
13.45\end{array}$ & $\begin{array}{l}\text { n } \\
11.41 \\
19.05 \\
\end{array}$ & $\begin{array}{l}30.50 \\
5.97 \\
\end{array}$ \\
\hline $\begin{array}{l}\text { Monetary policy shock } \\
\text { Technology shock }\end{array}$ & $\begin{array}{l}\text { two-year horizon } \\
8.28 \\
91.72\end{array}$ & $\begin{array}{l}0.18 \\
99.82\end{array}$ & $\begin{array}{l}2.31 \\
97.69\end{array}$ & $\begin{array}{l}10.79 \\
89.21\end{array}$ & $\begin{array}{l}\text { two-ye } \\
23.68 \\
15.07\end{array}$ & $\begin{array}{l}\text { ar horiz } \\
10.00 \\
11.98\end{array}$ & $\begin{array}{l}9.07 \\
15.04\end{array}$ & $\begin{array}{l}24.73 \\
6.23\end{array}$ \\
\hline
\end{tabular}

Table 3 reports the variance decompositions as implied by the calibrated general equilibrium model as well as the ones from the VAR estimation. The numbers are in percentage points. 
Table 4. Term Structure Factor Regression Results

\begin{tabular}{|c|c|c|c|c|}
\hline & \multicolumn{2}{|c|}{ Benchmark case } & \multicolumn{2}{|c|}{$\rho_{r}=0.99, \rho_{A}=0.95$} \\
\hline & Dlevel & $\Delta$ slope & $\Delta$ level & $\Delta$ slope \\
\hline$\varepsilon_{r, t}$ & $\begin{array}{c}0.0342 \\
(0.0242,0.0442)\end{array}$ & $\begin{array}{c}-0.2512 \\
(-0.2577,-0.2450)\end{array}$ & $\begin{array}{c}0.4622 \\
(0.2952,0.4714)\end{array}$ & $\begin{array}{c}-0.2064 \\
(-0.2186,-0.1942)\end{array}$ \\
\hline$\varepsilon_{r, t-1}$ & $\begin{array}{c}-0.0175 \\
(-0.0272,-0.0067)\end{array}$ & $\begin{array}{c}0.1268 \\
(0.1207,0.1336)\end{array}$ & $\begin{array}{c}-0.0084 \\
(-0.0203,0.0044)\end{array}$ & $\begin{array}{c}0.0332 \\
(0.0205,0.0445)\end{array}$ \\
\hline$\varepsilon_{r, t-2}$ & $\begin{array}{c}-0.0087 \\
(-0.0188,0.0018)\end{array}$ & $\begin{array}{c}0.0624 \\
(0.0562,0.0686)\end{array}$ & $\begin{array}{c}-0.0061 \\
(-0.0177,0.0079)\end{array}$ & $\begin{array}{c}0.0172 \\
(0.0044,0.0293)\end{array}$ \\
\hline$\varepsilon_{r, t-3}$ & $\begin{array}{c}-0.0043 \\
(-0.0139,0.0052)\end{array}$ & $\begin{array}{c}0.0310 \\
(0.0244,0.0377)\end{array}$ & $\begin{array}{c}-0.0052 \\
(-0.0183,0.0070)\end{array}$ & $\begin{array}{c}0.0094 \\
(-0.0020,0.0205)\end{array}$ \\
\hline$\overline{A d j} . R^{2}$ & $\begin{array}{c}0.1703 \\
(0.1015,0.2500)\end{array}$ & $\begin{array}{c}0.9359 \\
(0.9261,0.9440)\end{array}$ & $\begin{array}{c}0.6462 \\
(0.3397,0.7516)\end{array}$ & $\begin{array}{c}0.7767 \\
(0.7312,0.8107)\end{array}$ \\
\hline
\end{tabular}

Table 4 displays coefficients obtained in regressing the simulated "level" and "slope" on the simulated current and lagged monetary policy shocks. Both the median and the $90 \%$ confidence bands are reported, based on 1000 simulation draws (each of which 300 months long). 
Figure 1: Responses of Macroeconomic Variables in the VAR Estimations
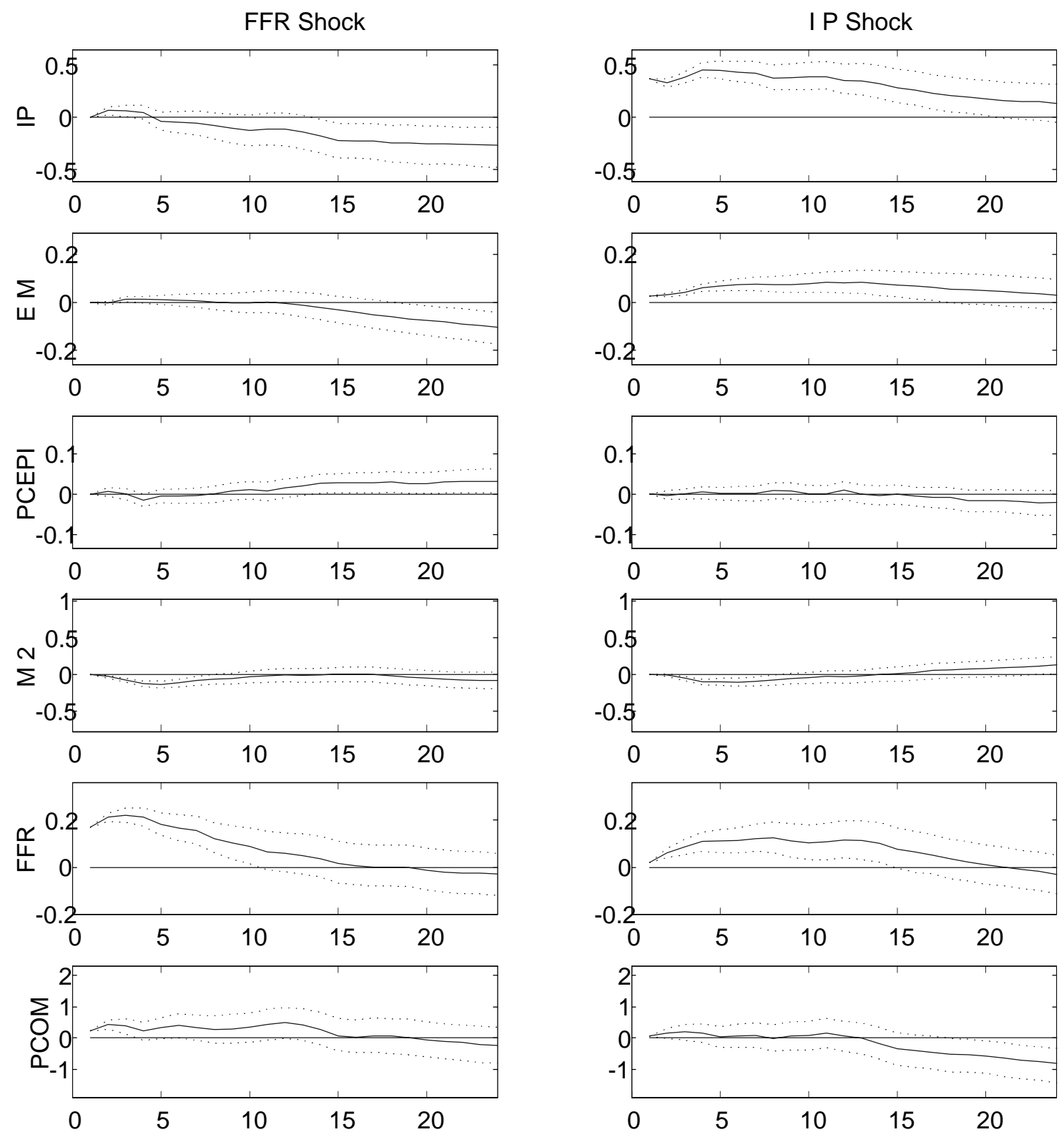
Figure 2: Responses of the Term Structure in the VAR Estimations
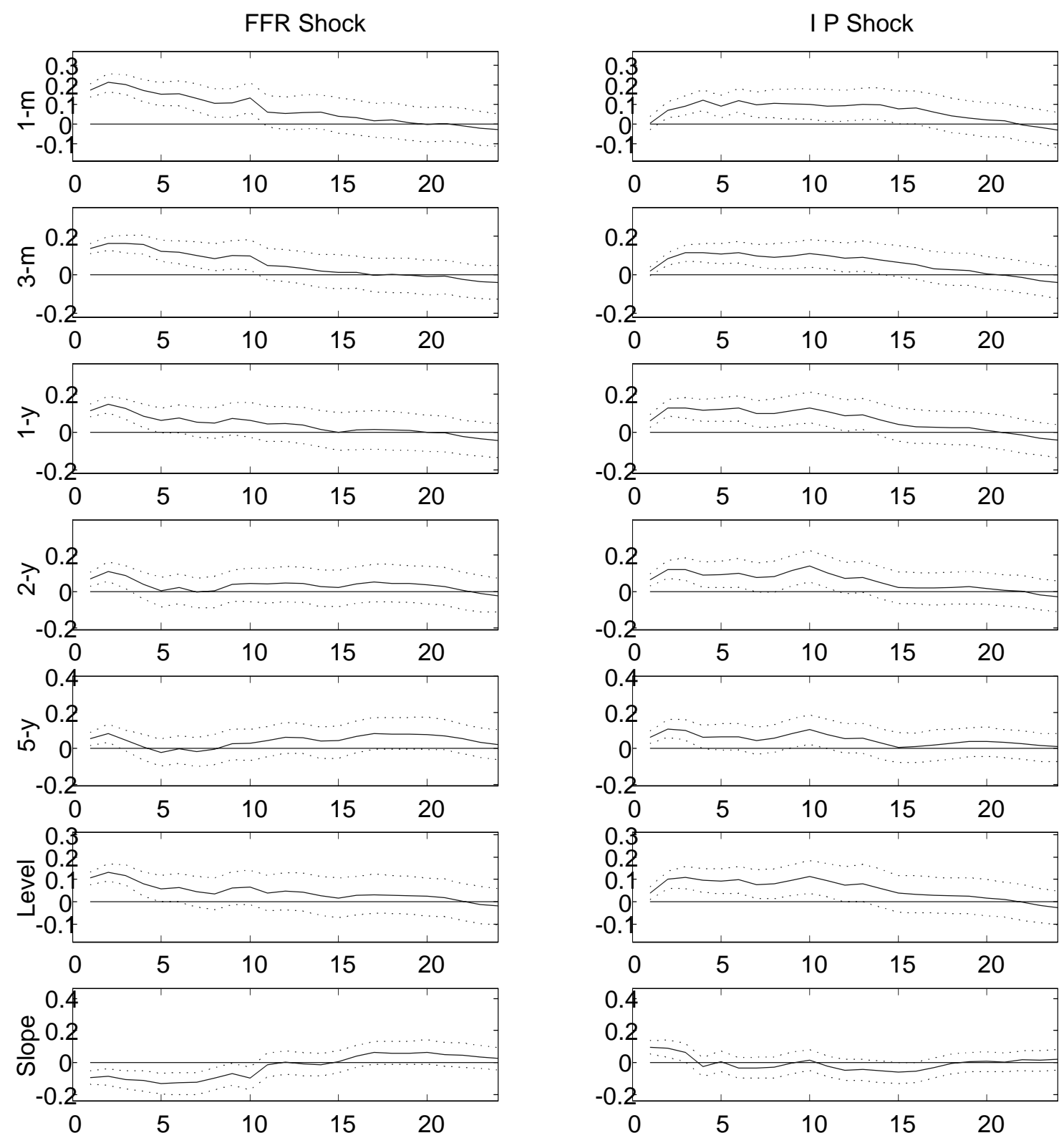
Figure 3: Responses of Macroeconomic Variables to Macro Shocks in the Calibrated Model
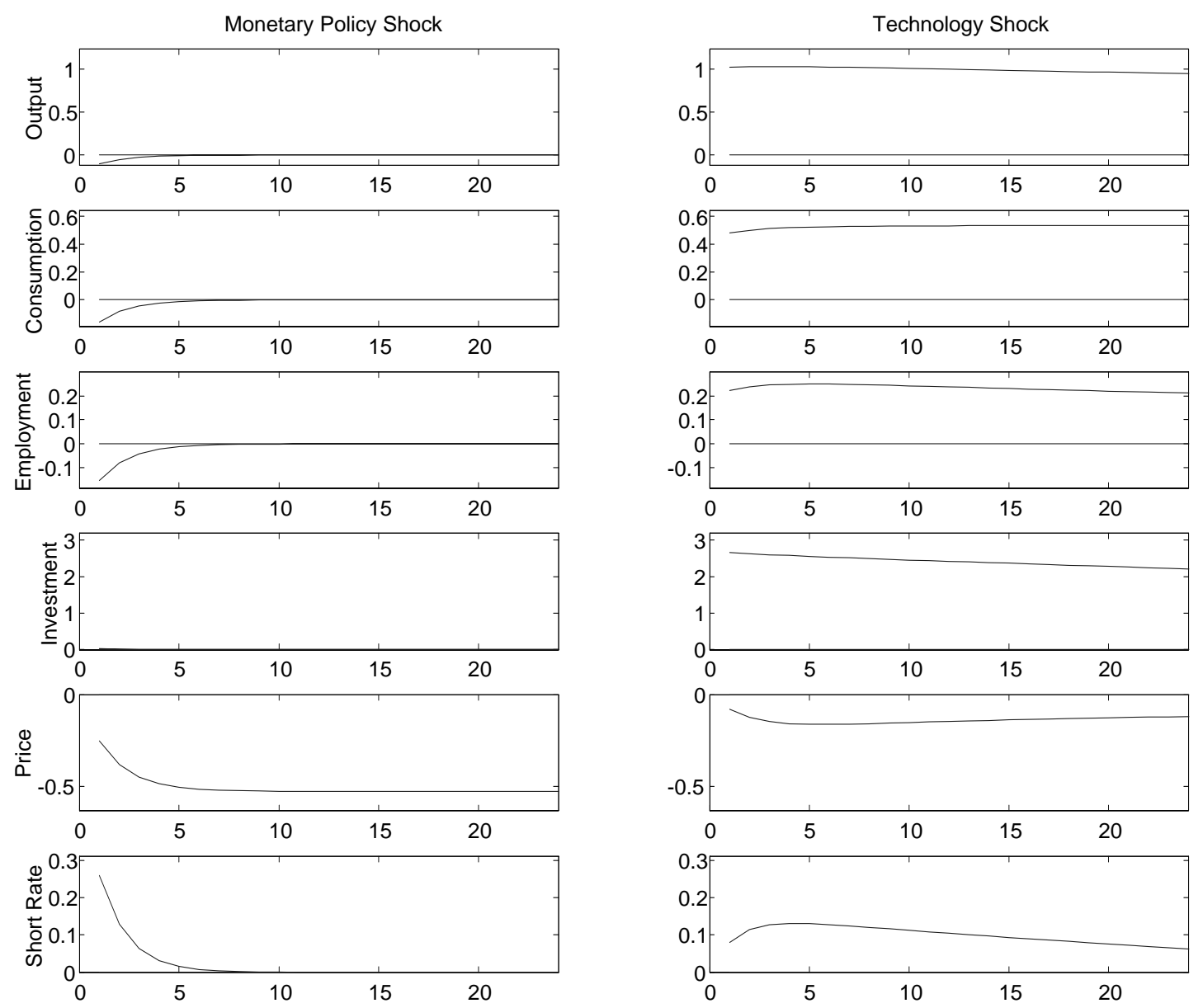
Figure 4: Instantaneous Responses of the Term Structure to Macro Shocks

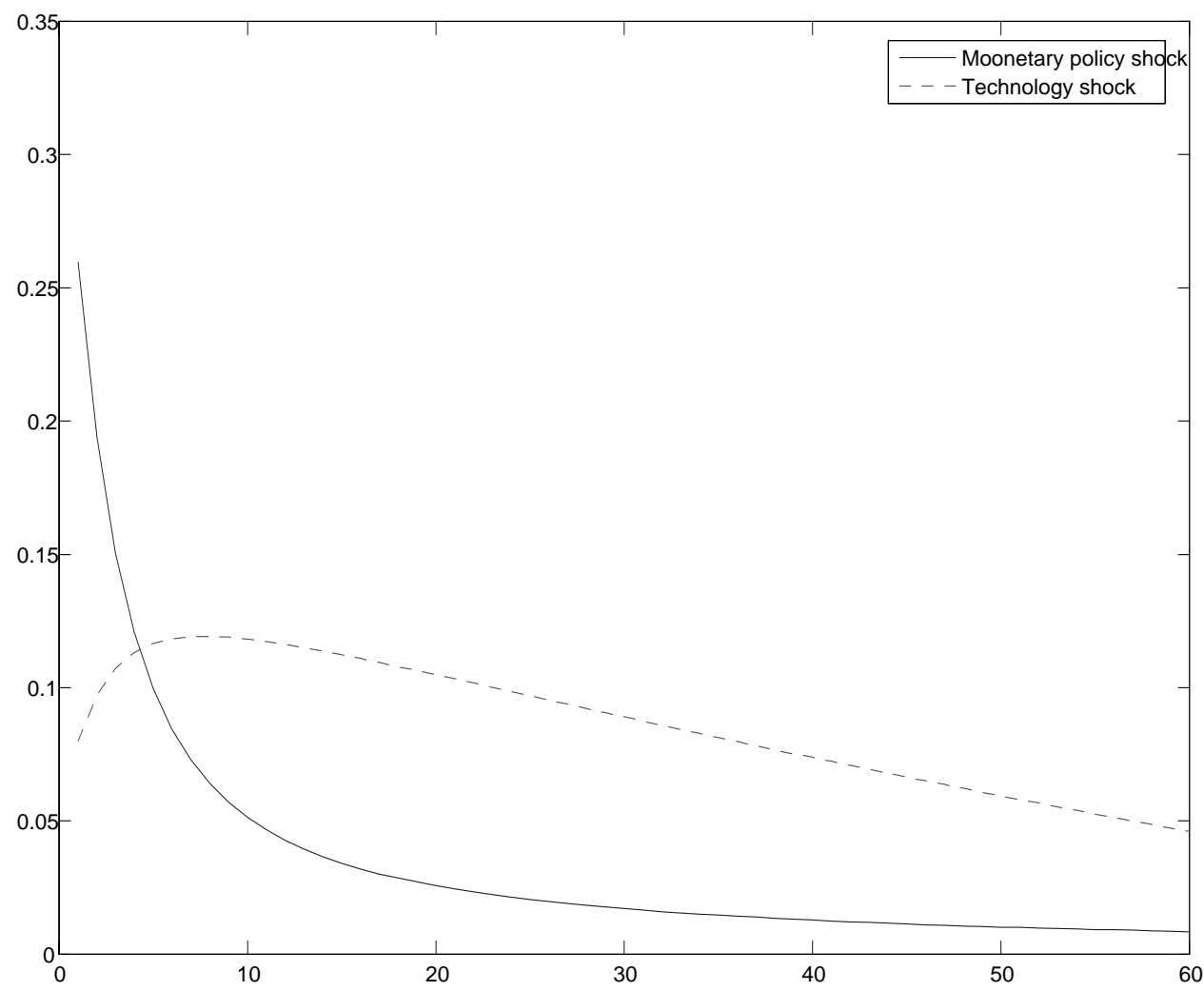


Figure 5: Responses of the Term Structure to Macro Shocks in the Calibrated Model
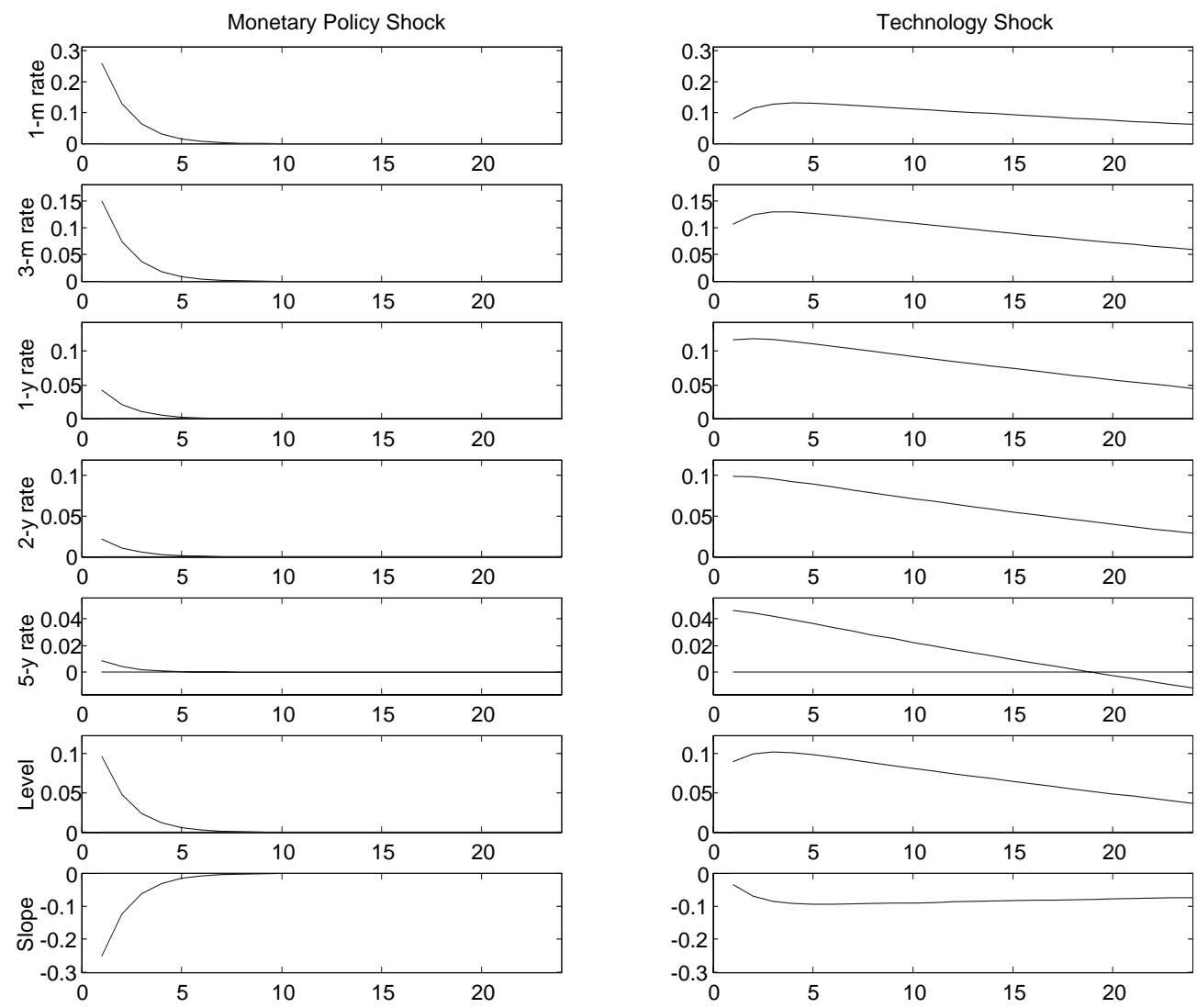


\section{Appendix: First-order Conditions of the General Equilibrium Model}

Let $\lambda_{t}, \phi_{l, t}$ denote the Lagrangian multipliers associated with constraints (3.1) and (3.2), respectively. The first-order conditions of the representative household are

For $C_{t}$ :

$$
U_{c, t}=\lambda_{t}\left[1+\theta(\omega+1) V_{t}^{\omega}\right]
$$

For $L_{t}$ :

$$
U_{l, t}=\phi_{l, t}
$$

For $N_{t}$ :

$$
\frac{W_{t}}{P_{t}} \lambda_{t}=\phi_{l, t}
$$

For $M_{t}$ :

$$
\frac{\lambda_{t}}{P_{t}}\left(1-\theta \omega V_{t}^{\omega+1}\right)=\beta E_{t}\left\{\frac{\lambda_{t+1}}{P_{t+1}}\right\}
$$

For $B_{1, t}$ :

$$
b_{1, t} \frac{\lambda_{t}}{P_{t}}=\beta E_{t}\left\{\frac{\lambda_{t+1}}{P_{t+1}}\right\}
$$

For $B_{j, t}$ :

$$
b_{j, t} \frac{\lambda_{t}}{P_{t}}=\beta E_{t}\left\{b_{j-1, t+1} \frac{\lambda_{t+1}}{P_{t+1}}\right\} \quad j=2, \ldots, J
$$

The first-order conditions for the intermediate firm $i$ are

For $N_{i t}$ :

$$
\left(\rho_{t} \frac{P_{i, t}}{P_{t}}+\xi_{i, t} \frac{1}{C_{t}^{*}}\right)\left(1-A C_{i, t}^{P}\right)(1-\alpha) A_{t} K_{i, t-1}^{\alpha} N_{i, t}^{-\alpha}=\frac{W_{t}}{P_{t}} \rho_{t}
$$

For $I_{i t}$ :

$$
\left(\rho_{t} \frac{P_{i, t}}{P_{t}}+\xi_{i, t} \frac{1}{C_{t}^{*}}\right)\left(1+\frac{3 \chi_{K}}{2} \frac{I_{i, t}^{2}}{K_{i, t-1}^{2}}\right)=\varphi_{i, t}
$$

For $K_{i t}$ : 
$\beta E_{t}\left\{\left(\rho_{t+1} \frac{P_{i, t+1}}{P_{t+1}}+\xi_{i, t+1} \frac{1}{C_{t+1}^{*}}\right)\left[\left(1-A C_{i, t+1}^{P}\right) \alpha A_{t+1} K_{i, t}^{\alpha-1} N_{i, t+1}^{1-\alpha}+\chi_{K} \frac{I_{i, t+1}^{3}}{K_{i, t}^{3}}\right]+\varphi_{i, t+1}(1-\delta)\right\}=\varphi_{i, t}$

For $P_{i, t}$ :

$$
\begin{aligned}
& \rho_{t} \frac{C_{i, t}^{*}}{P_{t}}+\xi_{i, t} \eta\left(\frac{P_{i, t}}{P_{t}}\right)^{-\eta-1} \frac{1}{P_{t}}+\left(\rho_{t} \frac{P_{i, t}}{P_{t}}+\xi_{i, t} \frac{1}{C_{t}^{*}}\right)\left(-\frac{\partial A C_{i, t}^{P}}{\partial P_{i, t}}\right) A_{t} K_{i, t-1}^{\alpha} N_{i, t}^{1-\alpha} \\
& +\beta E_{t}\left\{\left(\rho_{t+1} \frac{P_{i, t+1}}{P_{t+1}}+\xi_{i, t+1} \frac{1}{C_{t+1}^{*}}\right)\left(-\frac{\partial A C_{i, t+1}^{P}}{\partial P_{i, t}}\right) A_{t+1} K_{i, t}^{\alpha} N_{i, t+1}^{1-\alpha}\right\}=0
\end{aligned}
$$

where $\xi_{i, t}$ and $\varphi_{i, t}$ are the Lagrangian multipliers associated with constraint (2.9) and (2.13), respectively.

In a symmetric equilibrium, we have $P_{i, t}=P_{t}, K_{i, t}=K_{t}, N_{i, t}=N_{t}, C_{i, t}^{*}=C_{t}^{*}, \rho_{t}=\lambda_{t}$, and $\varphi_{i, t}=\varphi_{t}$. In addition, there is an aggregate resource constraint

$$
y_{t}=A_{t} K_{i, t-1}^{\alpha} N_{i, t}^{1-\alpha}-\Phi=\frac{C_{t}^{*}+I_{i, t}+A C_{t}^{K}}{1-A C_{t}^{P}}
$$

The dynamics of the variables at the equilibrium are then characterized by first-order conditions (A1)-(A10) and constraints (3.1), (3.2), (3.6), (3.8), (3.10), (3.15), (3.18) and (A11), as well as equations (3.9), (3.16) and (3.17) as the stochastic processes of the exogenous macroeconomic shocks. 